\title{
Association between Antenatal Care and Infant Mortality in Bangladesh: Multivariate Survival Regression Analysis
}

\author{
A H M Musfiqur Rahman Nabeen \\ Lecturer, Pabna University of Science and Technology, Pabna-6600, Bangladesh \\ Most. Sonia Khatun \\ Lecturer, Pabna University of Science and Technology, Pabna-6600, Bangladesh \\ Md. Shahajada Mia \\ Lecturer, Pabna University of Science and Technology, Pabna-6600, Bangladesh
}

Md. Maidul Husain

Lecturer, Bangabandhu Sheikh Mujibur Rahman Science and Technology University, Gobra-8100, Bangladesh

DOI: $10.31364 / \mathrm{SCIRJ} / \mathrm{v} 7 . \mathrm{i7} .2019 . \mathrm{P} 0719668$

http://dx.doi.org/10.31364/SCIRJ/v7.i7.2019.P0719668

\begin{abstract}
There is a significant improvement in infant survival over several decades in Bangladesh but the rate of infant mortality is still at unsatisfactory level. In many developing countries where primary healthcare requirements including antenatal care services are not generally available the infant mortality rate is not at acceptable level. Antenatal care is very important both for the health of mothers and children. Using Bangladesh Demographic and Health Survey (BDHS), 2014 data, this study made an attempt to examine the relationship between antenatal care and infant mortality employing survival regression model. Estimation results suggest that the children whose mothers did not receive antenatal care are about three times as likely to die during infancy than the children whose mothers received antenatal care during pregnancy period $(\mathrm{HR}=2.84$, 95\% CI: 2.14, 3.63), controlling for sex of the child, birth status, skilled birth assistance, birth order number, mother's age at birth, BMI, education level, wealth status, type of place of residence and region. The results also indicate that antenatal care is significantly negatively associated with infant mortality without controlling other risk factors. Hence the availability of antenatal care associated logistic supports should be increased at the peripheral level to improve the child survival in Bangladesh.
\end{abstract}

Keywords: Antenatal care, infant mortality, survival regression, hazard ratio, Bangladesh.

\section{Introduction}

Children play vital role for the overall development of any country. Thus any nation should ensure their healthy growth. Globally, child mortality rates have been decreased over the last several decades. In spite of this improvement in child survival the rates of infant and child mortality remain unacceptably high in many developing countries ${ }^{1}$. In Bangladesh, the infant mortality rate was 34 per 1000 live births in the year 2014 whereas it was 43 and 52 in 2011 and 2007 respectively ${ }^{2}$. Despite this reduction in infant mortality, the degree of infant mortality rate is not satisfactory in Bangladesh compared to the other developing countries ${ }^{3}$. Hence Bangladesh needs more initiatives to achieve further improvements in this regard of infant mortality.

The health care systems of many developing countries are struggling to provide basic public health facilities ${ }^{3}$. In case of mothers and children the health care condition is more critical ${ }^{4}$. In most of the developing countries, 
maternal and child health care services such as antenatal care, delivery care, and postnatal care are not available $^{5-6}$. Antenatal care (ANC) is the most important primary health care service for any pregnant mother. World Health Organization (WHO) recommended that at least four ANC visits during the pregnancy period is needed to ensure a safe motherhood ${ }^{7}$.It includes regular monitoring and variety of routine check-up of the mother and her baby during the pregnancy period. Therefore, women who receive antenatal care have more chance to learn about their pregnancy and have more opportunities to diagnose health problems and to be treated early. Lack of antenatal care is frequently associated with the premature delivery, pregnancy complications, maternal and neonatal child mortality ${ }^{8}$. The children whose mothers take proper antenatal care are less likely to be born as premature and are less likely to die before celebrating their first birthday than the mothers who take inadequate antenatal care ${ }^{9-10}$.

Bangladesh is one of the most densely populated countries in the world and it is really struggling against extreme poverty. Despite severe poverty and over population it is observed that Bangladesh is improving in the field of maternal health programs but the vast majority of the women do not have adequate access to antenatal care services yet. Most of the infant mortality occurs due to severe infections, premature births, low birth weight, complicated pregnancies and deliveries ${ }^{11}$. These problems are directly related with antenatal care and the situation is more serious among the poor and peripheral women where availability of ANC services is limited. Most of the infant mortality can be prevented by providing proper antenatal care services to the pregnant mothers. Both in developed and developing countries, previous research studies have shown negative associations between antenatal care and infant mortality ${ }^{12-14}$. These studies did not account for different combinations of factors such as socioeconomic and demographic characteristics of the children and mothers. This study made an attempt to take into account the different combinations of risk factors to examine the relationship between antenatal care and infant mortality using data from Bangladesh Demographic and Health Survey (BDHS), 2014 ${ }^{15}$. The study also examines how the gender of the child, birth status, delivery without skilled birth assistance, birth order number, mother's age at birth, BMI, education, wealth status, type of place of residence and geographic region are associated with infant mortality.

\section{Data and Methods}

Secondary data extracted from Bangladesh Demographic and Health Survey (BDHS), 2014 is used for the analysis of this study which was conducted by National Institute of Population Research and Training (NIPORT), under the Ministry of Health and Family Welfare, Bangladesh. It was implemented by Mitra and Associates, a research firm of Bangladesh located in Dhaka. Technical support was provided by Macro International Inc., a private research firm located in Calverton, Maryland, USA; through the MEASURE DHS program. Economical support for the survey was given by the U.S. Agency for International Development (USAID). For conducting the survey, Bangladesh was stratified into 20 strata where each stratum is made up of enumeration areas (EAs). It followed a two-stage stratified sampling procedure where at the first stage; the survey randomly selected 600 EAs (among them 207 in urban areas and 393 in rural areas) with probability proportional to the EA size. In the second stage of sampling, a systematic sample of 30 households was selected on average from each enumeration area. Finally, the information of 17863 ever-married women aged 12 to 49 year was collected from the selected households. The BDHS-2014 also collected demographic, socioeconomic, and health-related information of the women.

The analysis uses information on 4256 childbirth born within 5 years proceeding to the survey (which is approximate to the calendar years 2010-2014). The children whose information was insufficient or missing were excluded. Each mother interviewed in the survey was asked to give a detailed history of all her live births in chronological order, including whether a birth was multiple or single, gender of the child, survival status, date of birth, age of the child on the date of interview if alive, and if not alive, age at the time of death. This information from the birth history is used to calculate infant mortality rate (IMR). Antenatal care status is evaluated by whether the mothers received antenatal care during pregnancy from a professional health care 
service provider such as a doctor, nurse, midwife, family welfare visitor, family welfare assistant, health assistant, medical assistant etc. or did not receive antenatal care from professional service providers. To ensure safe motherhood, at least four ANC visits during the pregnancy period are recommended. Hence, if a mother received four or more times antenatal care from a professional health service provider then ANC is categorized as "Yes" otherwise "No".

Child survival is correlated with child's characteristics, mother's characteristics and other socioeconomic and regional factors. Hence the relationship between antenatal care and infant mortality are estimated after adjusting for the effects of other potentially confounding factors. These factors include gender of child (boy, girl), birth status (single, multiple), skilled birth assistance at delivery (no, yes), birth order number $(1,2,3,4+)$, mother's age at birth $\left(<20,20-30,30^{+}\right)$, mother's body mass index (BMI) $(18.5-24.9,<18.5, \geq 25.0 \mathrm{~kg} / \mathrm{m} 2)$, mother's education level (no education, primary, secondary, higher), household wealth index (poorest, poor, middle, rich, richest), type of place of residence (urban, rural) and region (Barisal, Chittagong, Dhaka, Khulna, Rajshahi, Rangpur, Sylhet). It should be noted that Principle Component Analysis (PCA) is used to estimate household wealth index from the household durable asset ${ }^{2}$. In case of skilled birth assistance (SBA) it is considered whether women received the assistance from doctor, nurse, family welfare visitor (FWV), family welfare assistant (FWA), medical assistant/sub-assistant and community skill birth attendant (CSBA). If at least one of the above skilled persons presents at the time of delivery then SBA is 'yes' otherwise 'no'. Using parametric multivariate survival regression model with Weibull hazard function the association of ANC and other confounding factors on infant mortality is estimated and results are presented as hazard ratios (HR) with $95 \%$ confidence intervals (CI). The multivariate survival regression model is described below.

\section{Survival Regression Model}

The most popular survival regression model using hazard function is the multiplicative hazard model or proportional hazard model. Under this model, covariates $x=\left(x_{1}, \ldots, x_{j}, \ldots, x_{p}\right)^{\prime}$ act multiplicatively on the hazard function. Let $T$ be the survival time to occur an event of interest and $x=\left(x_{1}, \ldots, x_{j}, \ldots, x_{p}\right)^{\prime}$ be the $p \times 1$ vector of covariates with regression coefficient vector $\beta=\left(\beta_{1}, \ldots, \beta_{j}, \ldots, \beta_{p}\right)^{\prime}$.

Suppose that $h_{0}(t)$ is the baseline hazard function. Under proportional hazard model, hazard function at time point $t$ in the presence of covariates $x$ can be written as

$$
h(t \mid x)=h_{0}(t) C(x)
$$

where $C(x)$ is the positive valued function of $x$ such that $C(x)=1$ in the absence of covariates $x$. According to $\operatorname{Cox}^{16}$ the choice of $C(x)$ is

$$
C(x)=e^{\beta^{\prime} x}=e^{\sum_{j=1}^{p} X_{j} \beta_{j}} .
$$

Thus the equation (i) is a multivariate survival regression model and the hazard ratio can be presented as $H R=\frac{h\left(t \mid x_{1}\right)}{h\left(t \mid x_{2}\right)}$, where $X_{1}=\left(x_{11}, \ldots, x_{1 j}, \ldots, x_{1 p}\right)^{\prime}$ and $X_{2}=\left(x_{21}, \ldots, x_{2 j}, \ldots, x_{2 p}\right)^{\prime}$ be two vectors of covariates associated with group/individual 1 and group/individual $2\left[X_{1} \neq X_{2}\right]$.

\section{Results}

The sample distribution of children born in the 5 years preceding the survey BDHS, 2014 by antenatal care and other selected covariates are shown in Table 1. The infant mortality rates per 1000 live births for different covariates are also presented in this table. Percentage distribution of number of ANC visits of mothers is shown in Figure 1. It is clear from the figure that approximately one third $(32 \%)$ of the mothers received antenatal care but $68 \%$ of them didn't receive it during their pregnancy period. About $51 \%$ were male children and $49 \%$ were females. Among all children $98 \%$ were born as singleton whereas only about $2 \%$ were born as multiple births. Only $37 \%$ of births received health care facility from skilled birth attendant at the time of delivery. Twenty nine percent of children were first order births, and another $28 \%$ were fourth or higher order. More than two-thirds (72\%) of the births were from mothers whose age were below 20 years at the time of birth, about $25 \%$ were 
from mothers aged 20-30 years, and the remaining 1.5\% were from mothers aged more than 30 years. Approximately fifty-seven percent of the births were to mothers with normal BMI index $(18.5-24.9 \mathrm{~kg} / \mathrm{m} 2)$. Only $11 \%$ mothers were higher educated on the other hand $18 \%$ mothers were illiterate. It is also observed that about $26 \%$ of children were born in the poorest family that is consistent with the concept that fertility rate is higher in the poorer households, $19 \%$ were born in middle-class family and $14 \%$ were born in the richest family. In case of type of place of residence, $74 \%$ percent of births were in rural areas and other $26 \%$ were from the urban area. According to geographic division, about $16 \%$ of the births were in Dhaka division, $20 \%$ were in Chittagong division, and 12\% were in Rajshahi and Rangpur division, 11\% were in Khulna and Barisal division whereas $16 \%$ in Sylhet division.

Figure 1. Percentage distribution of number of ANC visits of mothers.

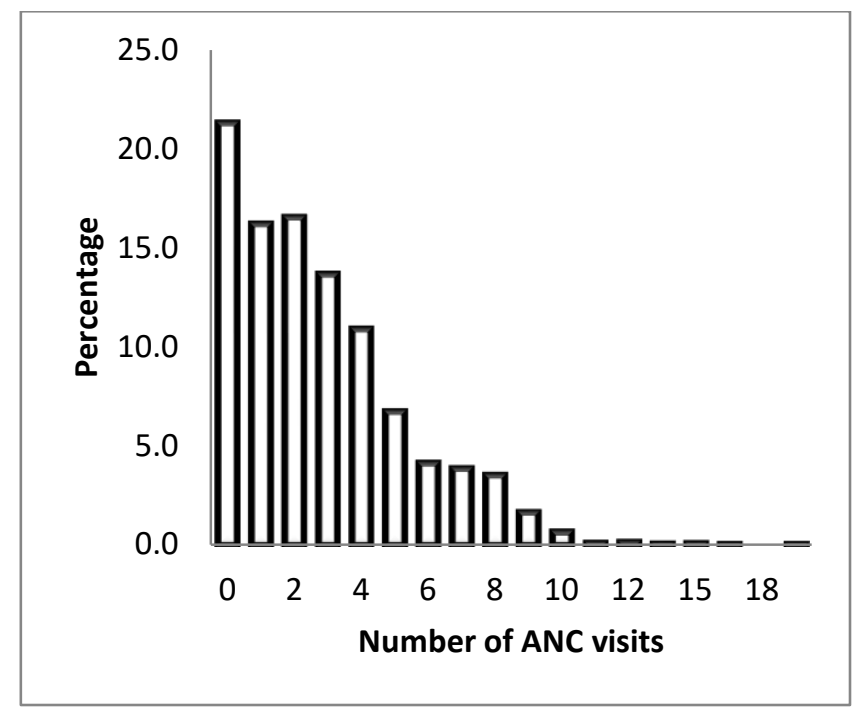

In the case of infant mortality rate (IMR), on average three in every 100 children born in Bangladesh (33 per 1000 live births) cannot celebrate their first birthday. This figure shows one of the greater infant mortality rates within the nations of South Asia. It is observed that infant mortality rate for the mothers who didn't receive antenatal care is 41 per 1000 live births but it is only 17 per 1000 live birth for the mothers who received antenatal care. In other words, children of mothers who did not receive antenatal care during their pregnancy period were about 2.5 times as likely to die during infancy as the children whose mothers received antenatal care. Thus there is a significant difference of IMR between these two groups of mothers. The infant mortality rate is higher among male children (37) than among female children (30). Consistent with the expectation, infant mortality rate is very high among the multiple birth children 278 per 1000 live births compared with only 28 per 1000 live births among the single birth. Mothers receiving skilled birth assistance at the time of delivery are associated with lower infant mortality rate. There is a U-shaped association between infant mortality rate and child's birth order number. Children were born to the older mothers $\left(30^{+}\right.$years old) are at higher risk of infant mortality. Infant mortality rate among the children of undernourished mothers and overweight mothers are 50 and 31 per 1000 live births respectively. As expected infant mortality rate is highly negatively associated with maternal education, with the increase of mother's education level the IMR decreases. The probability of death before 1 year of age for children born in the poorest family is higher than children born in the richest family. Infant mortality rate is slightly higher in the urban area than in rural area and it is considerably higher in Dhaka and Sylhet division than the other geographical regions. 
Table 1.Sample distribution and infant mortality rates among children born during 2010-2014 by selected covariates in Bangladesh

\begin{tabular}{|c|c|c|c|}
\hline Covariate & Frequency & Percentage (\%) & IMR/1,000 live births \\
\hline Bangladesh & 4256 & & 33.45 \\
\hline $\begin{array}{l}\text { Antenatal care } \\
\text { Yes } \\
\text { No }\end{array}$ & $\begin{array}{l}1390 \\
2866\end{array}$ & $\begin{array}{l}32.68 \\
67.32\end{array}$ & $\begin{array}{l}17.68 \\
41.76\end{array}$ \\
\hline $\begin{array}{l}\text { Gender of child } \\
\text { Boy } \\
\text { Girl }\end{array}$ & $\begin{array}{l}2158 \\
2098\end{array}$ & $\begin{array}{l}50.71 \\
49.29 \\
\end{array}$ & $\begin{array}{l}37.34 \\
30.09\end{array}$ \\
\hline $\begin{array}{l}\text { Birth status } \\
\text { Single } \\
\text { Multiple }\end{array}$ & $\begin{array}{c}4172 \\
84\end{array}$ & $\begin{array}{c}98.02 \\
1.98\end{array}$ & $\begin{array}{c}28.34 \\
278.67\end{array}$ \\
\hline $\begin{array}{l}\text { Skilled birth assistance } \\
\text { Yes } \\
\text { No }\end{array}$ & $\begin{array}{l}1594 \\
2662\end{array}$ & $\begin{array}{l}37.45 \\
62.55\end{array}$ & $\begin{array}{l}30.80 \\
35.65\end{array}$ \\
\hline $\begin{array}{l}\text { Birth order number } \\
1^{\text {st }} \\
2^{\text {nd }} \\
3^{\text {rd }} \\
\text { Other }\end{array}$ & $\begin{array}{c}1221 \\
1096 \\
747 \\
1192\end{array}$ & $\begin{array}{l}28.70 \\
25.74 \\
17.55 \\
28.01\end{array}$ & $\begin{array}{l}41.45 \\
31.76 \\
23.05 \\
35.73\end{array}$ \\
\hline $\begin{array}{l}\text { Mother's age at birth } \\
<20 \\
20-30 \\
30^{+}\end{array}$ & $\begin{array}{l}3092 \\
1098 \\
65\end{array}$ & $\begin{array}{c}72.66 \\
25.80 \\
1.54\end{array}$ & $\begin{array}{l}36.87 \\
30.81 \\
41.68\end{array}$ \\
\hline $\begin{array}{l}\text { Mother's BMI }\left(\mathbf{k g} / \mathbf{m}^{2}\right) \\
<18.5 \\
18.5-24.9 \\
>24.9\end{array}$ & $\begin{array}{c}1688 \\
2455 \\
298\end{array}$ & $\begin{array}{c}35.30 \\
57.70 \\
7.00\end{array}$ & $\begin{array}{l}50.23 \\
23.19 \\
31.86\end{array}$ \\
\hline $\begin{array}{l}\text { Mother's education level } \\
\text { No education } \\
\text { Primary or less } \\
\text { Secondary } \\
\text { Higher }\end{array}$ & $\begin{array}{c}794 \\
1155 \\
1809 \\
490\end{array}$ & $\begin{array}{l}18.66 \\
27.14 \\
42.50 \\
11.45\end{array}$ & $\begin{array}{l}41.89 \\
34.67 \\
29.14 \\
22.55\end{array}$ \\
\hline $\begin{array}{l}\text { Wealth status } \\
\text { Richest } \\
\text { Rich } \\
\text { Middle } \\
\text { Poor } \\
\text { Poorest }\end{array}$ & $\begin{array}{c}626 \\
845 \\
819 \\
876 \\
1089\end{array}$ & $\begin{array}{l}14.70 \\
19.85 \\
19.22 \\
20.54 \\
25.59\end{array}$ & $\begin{array}{l}30.70 \\
27.23 \\
40.46 \\
33.95 \\
48.34\end{array}$ \\
\hline $\begin{array}{l}\text { Type of place of residence } \\
\text { Urban } \\
\text { Rural }\end{array}$ & $\begin{array}{l}1139 \\
3117\end{array}$ & $\begin{array}{l}26.76 \\
73.24\end{array}$ & $\begin{array}{l}40.54 \\
31.28\end{array}$ \\
\hline $\begin{array}{l}\text { Region } \\
\text { Barisal }\end{array}$ & 473 & 11.12 & 26.56 \\
\hline
\end{tabular}




\begin{tabular}{|l|l|l|l|}
\hline Chittagong & 849 & 19.93 & 32.76 \\
Dhaka & 702 & 16.49 & 41.99 \\
Khulna & 477 & 11.20 & 30.77 \\
Rajshahi & 527 & 12.39 & 27.56 \\
Rangpur & 539 & 12.66 & 32.15 \\
Sylhet & 687 & 16.14 & 49.23 \\
\hline
\end{tabular}

\section{Impact of antenatal care on infant survival}

Survival probabilities for the children before 12 months of age by their mothers receiving antenatal care are represented in Figure 2. The figure shows that there is a considerable difference of survival before 12 months of age between the children whose mothers received ANC and whose mothers didn't received ANC. The children whose mothers did not receive antenatal care having significantly lower survival probability than children of mothers who received antenatal care during their pregnancy period.

Figure 2. The Probability of infant survival before 12 months of age by antenatal care in Bangladesh, 2014

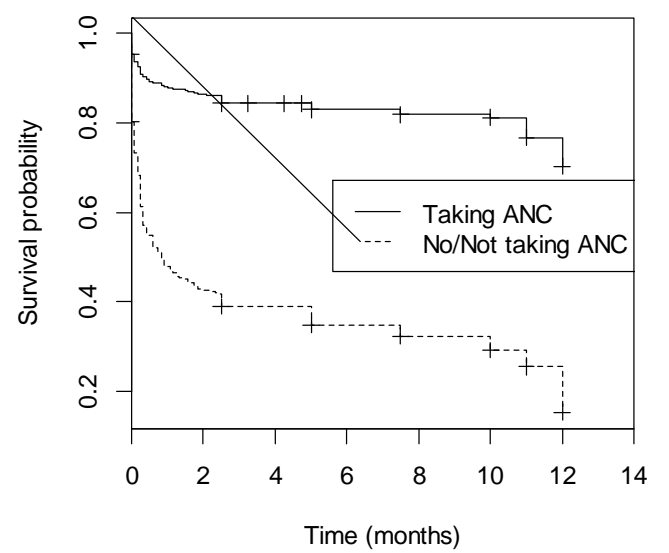

In Model 1 of Table 2, the unadjusted hazard ratio suggests that there is a strong negative association between taking proper antenatal care and infant mortality. Children of the mothers who did not receive antenatal care are about three times as likely to die in infancy as those of the mothers who received antenatal care $(\mathrm{HR}=2.84,95 \%$ CI: 2.14, 3.63). The effect of antenatal care on infant mortality remains large and statistically significant, when effects of child's gender, birth status, assistance by skilled birth attendant at the time of delivery, and birth order number are controlled for in Model 2. When these child characteristics are controlled it is observed that children of the mothers who did not receive antenatal care are 2.49 times more likely to die in infancy than those who received antenatal care. Besides, controlling for mother's age at birth, BMI, and educational status in Model 3 has little changing effect on the strength and the direction of the relationship (HR=2.38, 95\% CI: 1.81 , 3.12). In the full model (Model 4), after all the child, maternal, household, and geographical factors are controlled, the children of the mothers who did not receive antenatal care are about two and a half times as likely to die within the first year of life as those of the mothers who received antenatal care $(\mathrm{HR}=2.61,95 \% \mathrm{CI}$ : $1.93,3.43)$.

\section{Impact of other risk factors on infant survival}


In Model 4 from Table 2, when antenatal care and other risk factors are controlled, it is observed that the children whose mothers get skilled birth assistance at the time of delivery are less likely to die before reaching their $1^{\text {st }}$ birthday $(\mathrm{HR}=1.67,95 \% \mathrm{CI}: 1.20,2.26)$. Children of first order birth are more likely to die before celebrating their first birthday compared to the other children. Also maternal education has significant impact on infant mortality. The probability of dying an infant decreases with the increase of maternal education. Geographical region is also related with infant mortality. However, the size of these effects and relationship is small (Model 4). None of the other risk factors in the models has a statistically significant impact on the risk of infant mortality.

Table 2.Unadjusted and adjusted hazard ratio (HR) between antenatal care and infant survival before 12 months of age, controlling for other factors among children born during 2010-2014 in Bangladesh

\begin{tabular}{|c|c|c|c|c|}
\hline Covariate & & Hazard Rati & io $(95 \%$ CI $)$ & \\
\hline & Model 1 & Model 2 & Model 3 & Model 4 \\
\hline $\begin{array}{l}\text { Antenatal care } \\
\text { Yes (Ref) } \\
\text { No }\end{array}$ & $2.84(2.14,3.63)$ & $2.49(1.88,3.27)$ & $2.38(1.81,3.12)$ & $2.61(1.93,3.43)$ \\
\hline $\begin{array}{l}\text { Gender of child } \\
\text { Boy (Ref.) } \\
\text { Girl }\end{array}$ & & $0.93(0.77,1.21)$ & $0.92(0.75,1.19)$ & $0.96(0.76,1.19)$ \\
\hline $\begin{array}{l}\text { Birth status } \\
\text { Single } \\
\text { Multiple }\end{array}$ & & $4.08(1.55,7.26)$ & $4.28(1.67,7.33)$ & $3.98(1.45,7.06)$ \\
\hline $\begin{array}{l}\text { Skilled birth assistance } \\
\text { No (Ref.) } \\
\text { Yes }\end{array}$ & & $1.59(1.17,2.16)$ & $1.52(1.09,2.12)$ & $1.67(1.20,2.26)$ \\
\hline $\begin{array}{l}\text { Birth order number } \\
1^{\text {st }}(\text { Ref.) } \\
2^{\text {nd }} \\
3^{\text {rd }} \\
\text { Other } \\
\end{array}$ & & $\begin{array}{l}0.66(0.46,0.86) \\
0.64(0.44,0.89) \\
0.85(0.65,1.11)\end{array}$ & $\begin{array}{l}0.65(0.47,0.92) \\
0.57(0.36,0.88) \\
0.65(0.40,1.03) \\
\end{array}$ & $\begin{array}{l}0.53(0.37,0.79) \\
0.52(0.30,0.81) \\
0.56(0.33,0.91) \\
\end{array}$ \\
\hline $\begin{array}{l}\text { Mother's age at birth } \\
<20 \text { (Ref.) } \\
20-30 \\
30^{+}\end{array}$ & & & $\begin{array}{l}0.78(0.55,1.08) \\
1.41(0.83,2.48)\end{array}$ & \begin{tabular}{|l}
$0.88(0.61,1.21)$ \\
$1.65(0.87,3.12)$
\end{tabular} \\
\hline $\begin{array}{l}\text { Mother's BMI }\left(\mathbf{k g} / \mathbf{m}^{2}\right) \\
<18.5 \\
18.5-24.9 \text { (Ref.) } \\
>24.9\end{array}$ & & & $\begin{array}{l}1.16(0.94,1.40) \\
1.09(0.71,1.76)\end{array}$ & $\begin{array}{l}1.05(0.78,1.27) \\
0.97(0.59,1.64)\end{array}$ \\
\hline $\begin{array}{l}\text { Mother's education level } \\
\text { No education (Ref.) } \\
\text { Primary } \\
\text { Secondary } \\
\text { Higher }\end{array}$ & & & $\begin{array}{l}0.73(0.51,0.90) \\
0.67(0.48,0.87) \\
0.61(0.43,0.82)\end{array}$ & $\begin{array}{l}0.71(0.54,0.94) \\
0.68(0.50,0.93) \\
0.63(0.44,0.83) \\
\end{array}$ \\
\hline $\begin{array}{l}\text { Wealth status } \\
\text { Richest (Ref.) } \\
\text { Rich } \\
\text { Middle }\end{array}$ & & & & $\begin{array}{l}0.79(0.49,1.25) \\
1.07(0.66,1.68)\end{array}$ \\
\hline
\end{tabular}




\begin{tabular}{|l|l|l|l|}
\hline Poor & & & $0.73(0.46,1.15)$ \\
Poorest & & & $0.96(0.57,1.58)$ \\
\hline Type of place of residence & & & \\
Urban (Ref.) & & & $0.92(0.68,1.21)$ \\
Rural & & & \\
\hline Region & & & $1.22(0.78,2.02)$ \\
Barisal (Ref.) & & & $1.54(0.94,2.50)$ \\
Chittagong & & & $1.08(0.65,1.91)$ \\
Dhaka & & & $1.26(0.85,2.13)$ \\
Khulna & & & $1.12(0.71,1.92)$ \\
Rajshahi & & & $1.82(1.14,2.92)$ \\
Rangpur & & & \\
Sylhet & & & \\
\hline
\end{tabular}

\section{Discussion}

Estimation results indicate that receiving antenatal care at least four or more times from a health care professional during pregnancy period is associated with smaller risk of dying within the first 12 months of life among children born in the period from 2010 to 2014 in Bangladesh. The results of this study shows that infant mortality remains unacceptably high in Bangladesh, and the children whose mothers did not receive antenatal care are at greater risk of dying in infancy. The children whose mothers did not receive antenatal care are 2.84 times as likely to die during the first year of their life as the children whose mothers received antenatal care, controlling the factors of child's sex, birth status, birth order number, maternal education and nutritional status, and other factors. Without controlling these risk factors the association remains almost same both in strength and direction. These findings are consistent with the results from other studies ${ }^{17-18}$ and provide further evidence that antenatal care is one of the most important determinants of child survival in Bangladesh.

In the previous research studies, mother's education has been identified as one of the key factors in promoting child survival $^{6,10,19}$. This study also finds that maternal education have significant impact on the risk of infant mortality. Thus maternal education plays a vital role for the reduction of infant mortality in Bangladesh. Besides, this study suggests that children of first order birth are more likely to die before celebrating their first birthday than other children. Hence special care and supervision is necessary for the first born baby of a family.

The cross-sectional nature is one of the potential limitations of this study. While some of the characteristics used in this study, such as antenatal care, child's sex, mother's age at birth are fixed characteristics but other factors such as mother's education level, type of place of residence could have changed during the last 5 years. Notwithstanding these potential limitations, consistency in the direction and strength of the association between antenatal care and infant mortality suggests that improving primary health care at the community level, expanding maternal and child health services for the mothers will be the key factors for the improvement of child survival in Bangladesh. The findings of this research may help policy makers to make health care policy in Bangladesh such that mothers can receive antenatal care to reduce infant mortality.

\section{Acknowledgement}

We are greatly indebted to the Department of Statistics, Pabna University of Science and Technology for the permission of using its logistics support. We would also like to thank authorities of the National Institute of Population Research and Training (NIPORT), Bangladesh for allowing us to use BDHS, 2014 data.

\section{Reference}


1. United Nation Development Programme (2016), Human Development Report 2016. New York: UNDP.

2. Bangladesh Demographic and Health Survey (BDHS) Report (2014, 2011, 2007), Niport, Dhaka, Bangladesh; Mitra and Associates, Dhaka, Bangladesh.

3. World Bank (2016), World Development Report 2016. Washington, DC: World Bank.

4. Bryce, J., R. E. Black, N. Walker, Z. A.Bhutta, J. E. Lawn and R. W. Steketee, 2005. Can the world afford to save the lives of 6 million children each year? Lancet, 365, 2193-200.

5. Yucesoy, G., S. Ozkan, H.Bodur, T. Tan, E.Caliskan, B.Vuraland A. Corakci, 2005. Maternal and perinatal outcome in pregnancies complicated with hypertensive disorder of pregnancy: a seven year experience of a tertiary care center. Achieve Gynecology Obstetrics, 273, 43-49.

6. Hossain, M. K., M. R. Islam, M. N. Khan and M. R. Ali, 2015. Contribution of socio-demographic factors on antenatal care in Bangladesh: Modeling approach. Public Health Research, 5(4), 95-102.

7. World Health Organization (1994), World Health Report 1994. Geneva, World Health Organization.

8. Rahman, M., R. Islam and M. Rahman, 2010. Antenatal care seeking behaviour among slum mothers: A study of Rajshahi city corporation, Bangladesh. Sultan Qaboos University Medical Journal, 10(1), 50-56.

9. Mathai, M., 2005. Improving maternal and child survival in India. Indian Journal of Medical Research, 121, 624-7.

10. Akanda, M. A. S., 2010. Demand for antenatal care in Bangladesh: An application of two-part model. South Asian Journal of Population and Health, 3(1), 29-41.

11. Chowdhury, Q.H., R. Islam and K.Hossain, 2010. Socio-economic determinants of neonatal, post neonatal, infant and child mortality. International Journal of Sociology and Anthropoogyl, 27, 13571368.

12. Adam, T., S. S. Lim, S.Metha, Z. A.Bhutta, H.Fogstad, J. Zupan and G. L.Darmstandt, 2005. Cost effectiveness analysis of strategies for maternal and neonatal health in developing countries. British Medical Journal, 331(7525), 1107.

13. Rathavuth, H. and R. B. Martin, 2007. Impact of prenatal care on infant survival in Bangladesh. Maternal Child Health Journal, 11, 199-206.

14. Hossain, M. and M. Islam, 2008. Socio-economic variables affecting infants and children mortality in Bangladesh. Internet Journal of Health,9(2), http://ispub.com/IJH/9/2/5320.

15. Bangladesh Demographic and Health Survey (BDHS), 2014, Niport, Dhaka, Bangladesh; Mitra and Associates, Dhaka, Bangladesh.

16. Cox, D. R., 1972. Regression models and life-tables. Journal of the Royal Statistical Society, Series $\mathrm{B}, \mathbf{3 4}, 187-220$.

17. Eshleman, M.J., V. Poole and R.Davidhizar, 2005. An investigation of factors associated with infant mortality in two Midwest counties. Journal of Practical Nursing, 55, 5-10.

18. Kabir, R. and H. T. A. Khan, 2013. Utilization of Antenatal care among pregnant women of Urban Slums of Dhaka City, Bangladesh. Journal of Nursing and Health Science, 2(2), 15-19.

19. Pena, R., S. Wall and L.Persson, 2000. The effect of poverty, social inequality, and maternal education on infant mortality in Nicaragua, 1988-1993. American Journal of Public Health, 90, 649. 